\title{
Os Impactos da Ação Direta de Inconstitucionalidade no 3481 na Psicologia e na Sociedade
}

\author{
Ana Paula Porto Noronha ${ }^{1}$ \\ ${ }^{1}$ Universidade São Francisco, SP, Brasil. \\ Ana Cristina Resende ${ }^{2}$ \\ ${ }^{2}$ Pontifícia Universidade Católica de Goiás, GO, Brasil. \\ Katya Luciane de Oliveira ${ }^{3}$ \\ ${ }^{3}$ Universidade Estadual de Londrina, PR, Brasil. \\ Monalisa Muniz ${ }^{4}$ \\ ${ }^{4}$ Universidade Federal de São Carlos, SP, Brasil. \\ Caroline Tozzi Reppold ${ }^{5}$ \\ ${ }^{5}$ Universidade Federal de Ciências da Saúde de Porto Alegre, RS, Brasil.
}

\begin{abstract}
Resumo: Recentemente, o inciso III da Resolução n. 002/2003 do Conselho Federal de Psicologia (CFP) foi parcialmente considerado inconstitucional pelo Supremo Tribuna Federal a partir do julgamento da Ação Direta de Inconstitucionalidade (ADI 3481). Por sete votos a quatro, o Supremo decidiu pela liberar a comercialização dos testes psicológicos para a população em geral. Após apresentar informações, memoriais, medida cautelar e Ação de Embargo Declaratório, o CFP aguarda agora a modulação da decisão do STF. Desse modo, entende-se que é necessário desenvolver estratégias para que o acesso à informação científica possa ser disponibilizado, sem inviabilizar o uso dessa tecnologia profissional. Nesse artigo, enfatiza-se como a liberação da comercialização dos testes psicológicos possui potencial de gerar prejuízos para o indivíduo, para os profissionais da área, bem como pode vir a desnaturar os resultados que levaram anos de estudos científicos para ser alcançados, impactando na produção de conhecimento psicológico, mas, sobretudo, na sociedade que, em última instância, é a beneficiária dos serviços prestados pela psicologia. Para um melhor entendimento dessa problemática, o artigo detalha a ADI 3481 e seu histórico, como o uso inadequado dos testes e a falta de competência para o uso podem gerar consequências prejudiciais tanto para o indivíduo, no que se refere à autoaplicação do teste, quanto para a sociedade.
\end{abstract}

Palavras-chave: Avaliação psicológica, Ensino de avaliação psicológica, Testes Psicológicos, Validade.

\section{The Impacts of Direct Action of Unconstitutionality 3481 on Psychology and Society}

\begin{abstract}
The Direct Action of Unconstitutionality (DAU 3481) originated from the establishment of Item III of Resolution no. 002/2003 of the Federal Council of Psychology (CFP) as partially unconstitutional. By seven votes against four, the Brazilian Supreme Court (STF) regulated the commercialization of psychological tests to the population. After providing information, memorials, precautionary measure, and a Judgment Amendment Action, the CFP awaits the modulation of the STF decision. In this scenario, strategies for enabling access to scientific information while ensuring constitutional principles must be developed, without making the use of this professional technology unfeasible. This article emphasizes the negative effects of the psychological tests commercialization for both the individual and professionals in the field. Moreover, such measure also compromises instruments validity, a process that takes years of scientific studies to be achieved, impacting not only the production of psychological knowledge, but mainly the overall society - the beneficiary of the services provided by psychology. For a better understanding of this problem, this article details how the inappropriate use of the tests generates harmful consequences for the individual, regarding the self-use of the test, and for society, considering that psychological practice involves different assessments and testings.
\end{abstract}

Keywords: Psychological assessment, Teaching psychologial assessment, Validity. 


\title{
Los Impactos de la Acción Directa de Inconstitucionalidad 3481 en la Psicología y la Sociedad
}

\begin{abstract}
Resumen: El punto III de la Resolución n. 002/2003 del Consejo Federal de Psicología brasileño (CFP) fue considerado parcialmente inconstitucional por el Supremo Tribunal Federal (STF) a partir de la Acción Directa de Inconstitucionalidad (ADI 3481). Por siete votos contra cuatro, el STF aprobó la venta de pruebas psicológicas a la población en general. Tras presentada información, memoriales, medida cautelar y Acción Declaratoria de Embargo, el CFP espera la modulación de la decisión del STF. Así se entiende que es necesario desarrollar estrategias para que el acceso a la información científica pueda estar disponible, sin que esto haga inviable el uso de esta tecnología profesional. En este artículo, se enfatiza cómo la liberación de la comercialización de pruebas psicológicas tiene un fuerte potencial de generar daño al individuo, a los profesionales en el campo, así como puede desnaturalizar los resultados, que llevan años de estudios científicos para lograrlos, incidiendo en la producción de conocimiento psicológico, sobre todo en la sociedad que, en última instancia, es la que se beneficiaría de los servicios que brinda la psicología. Para una mejor comprensión de esta problemática, se detalló la ADI 3481 y su histórico sobre cómo el uso inadecuado de las pruebas y la falta de competencia para el uso pueden generar consecuencias nocivas tanto para el individuo, en lo que respecta al uso propio de la prueba, como para la sociedad.
\end{abstract}

Palabras clave: Evaluación psicológica, Enseñanza de la evaluación psicológica, Pruebas psicológicas, Validez.

\section{Da Constituição à inconstitucionalidade}

As constituições regulamentam a vida em sociedade, determinam quem e como se governa, estabelecendo os direitos e os deveres de todos os cidadãos de um país. Como exemplo de civilidade, elas permitem o funcionamento e a defesa das estruturas organizativas de uma sociedade e servem como código mantenedor da preservação da ordem (Negretto, 2012). Assim sendo, se por um lado a Constituição Federal regula a sociedade brasileira, por outro, nesses 33 anos de existência, essa mesma Constituição tem sido motivo de diferentes análises e interpretações, especialmente por parte das comunidades acadêmico-jurídicas.

Santos (2021), ao elucidar a ideia jurídica da Constituição sob a ótica social, escreve que é comum estudos que buscam compreender os impactos das decisões do Supremo Tribunal Federal e os caminhos lógicos de como os ministros efetivam sua decisão. Nessa perspectiva, estudar a interpretação dos preceitos contidos na Constituição Federal perpassa também a compreensão de aspectos que sofrem as consequências desses determinantes constitucionais. Por isso, a transversalidade analítica com diversas áreas do conhecimento é salutar para analisar e interpretar os impactos constitucionais. Caso contrário, embora as decisões do Supremo Tribunal Federal inclinem-se sempre para a defesa dos direitos humanos básicos, estas decisões também podem, dependendo das interpretações de seus próprios membros, diluir esses direitos ou retirá-los.

O controle da constitucionalidade consiste em garantir a supremacia da Constituição, de modo que prevaleça como parâmetro de controle o conteúdo constante da Constituição Federal. Assim, a falta de consonância do conteúdo da lei ou do ato normativo com a Constituição Federal leva à declaração inconstitucionalidade. Diante disso, Barroso (2019) elucida que a Ação Direta de Inconstitucionalidade (ADI) tem o papel de declarar a inconstitucionalidade de uma lei, de uma norma ou de parte de integrante delas. Assim, no entendimento de Barroso (2019), a ADI oferece elemento analítico que pode caminhar para uma nova interpretação do teor do texto constitucional.

Posto isto, o Plenário do Supremo Tribunal Federal (STF), no dia 5 de março de 2021, em sessão virtual, concluiu o julgamento da Ação Direta de Inconstitucionalidade $n^{\circ} 3481$. Esse julgamento declarou a 
inconstitucionalidade dos dispositivos contidos no inciso III e nos parágrafos $1^{\circ} \mathrm{e} 2^{\circ}$ do artigo 18 da Resolução no 002/2003 do CFP, considerados desproporcionais e ofensivos aos postulados constitucionais da liberdade de manifestação do pensamento e de acesso irrestrito à informação. Ou seja, o inciso da Resolução do CFP seria uma ofensa ao artigo $5^{\circ}$, incisos IV, IX e XIV, e aos artigos 215 e 220 da Constituição Brasileira.

Segue, na íntegra, o que foi considerado inconstitucional pelo STF:

Art. 18 - Todos os testes psicológicos estão sujeitos ao disposto nesta Resolução e deverão: III - ter sua comercialização e seu uso restrito a psicólogos regularmente inscritos em Conselho Regional de Psicologia. $\$ 1^{\circ}$ - Os manuais de testes psicológicos devem conter a informação, com destaque, que sua comercialização e seu uso são restritos a psicólogos regularmente inscritos em Conselho Regional de Psicologia, citando como fundamento jurídico o $\$ 1{ }^{\circ}$ do Art. 13 da Lei no 4.119/62 e esta Resolução. $\$ 2{ }^{\circ}$-Na comercialização de testes psicológicos, as editoras, por meio de seus responsáveis técnicos, manterão procedimento de controle onde conste o nome do psicólogo que os adquiriu, o seu número de inscrição no CRP e o(s) número(s) de série dos testes adquiridos (Conselho Federal de Psicologia [CFP], 2003).

A publicação da Ata de Julgamento do Plenário foi realizada no dia 16 de março de 2021, com a validação da decisão do relator ministro Alexandre de Moraes, que foi seguida pelos ministros Gilmar Mendes, Ricardo Lewandowski, Luiz Fux, Luís Roberto Barroso, Nunes Marques e Carmen Lúcia. Assim, foram sete votos a favor da liberação da comercialização dos testes psicológicos contra quatro votos que concordavam em manter a restrição de venda desses instrumentos aos psicólogos.

\section{Do entendimento da ADI-3481}

A ação foi movida em 2004, mediante um procedimento administrativo cível do Ministério Público Federal (MPF), por meio da Procuradoria do Município de Uberaba, com o objetivo de indagar as restrições impostas às livrarias e editoras quanto à comercialização dos testes psicológicos a não psicólogos. Mesmo que nessa ocasião o Conselho Federal de
Psicologia tenha prestado todas as elucidações das quais fora chamado a se pronunciar, ainda assim, o MPF entrou com requerimento junto ao Procurador Geral da República com a propositura de uma Ação Direta de Inconstitucionalidade, considerando o inciso III e aos parágrafos $1^{\circ} \mathrm{e} 2^{\circ}$ do artigo 18 da Resolução no 002/2003 do CFP.

No mês de setembro de 2017, após o processo ter tramitado por treze anos, passando por diferentes relatores até sua liberação para inclusão em pauta, o relator ministro Alexandre de Moraes apresentou seu voto pela procedência da ADI. Então, no ano de 2018, o CFP providenciou a elaboração de memoriais técnicos que foram protocolados e apresentados aos ministros. Com esses documentos, a entidade procurava trazer elementos elucidativos sobre a importância científica e social de se manter a restrição do acesso aos testes psicológicos para os não psicólogos. Esses documentos foram anexados ao processo, mas não compuseram o corpo dele, pois, pela regra jurídica, elementos novos não podem ser juntados pelas partes interessadas na ação após a liberação do processo para julgamento.

Tendo decorrido o período de 16 anos desde a propositura e o acolhimento da ADI, a ação foi julgada em 2021. Houve quatro votos divergentes da posição do ministro relator: os dos ministros Edson Fachin, Marco Aurélio, Dias Toffoli e Rosa Weber. Os ministros com votos divergentes seguiram uma linha de raciocínio que ponderava sobre a obrigação do diagnóstico psicológico ser uma prática controlada, já que o acesso aos materiais técnicos poderia atentar contra a segurança interna das técnicas, podendo levar a possíveis diagnósticos infundados. Houve a indicação de que o controle aos testes é algo praticado em outros países e que sua restrição preserva o diagnóstico, a orientação e o tratamento psicológico (Supremo Tribunal Federal [STF], 2021).

Contudo, a decisão do STF declarou a inconstitucionalidade de alguns dispositivos contidos na Resolução 02/2003 do Conselho Federal de Psicologia (CFP), qual seja, a restrição da comercialização dos testes psicológicos a não psicólogos. Tal fato obriga editoras, livreiros e entidades comerciais desta natureza a efetivarem a venda somente para esse público, conforme constava no Art. 18, III, \$§ $1^{\circ} \mathrm{e} 2^{\circ}$ da Resolução 02/2003.

A Resolução 02/2003, embora tenha sido revogada pela Resolução 09/2018, tinha parte do seu conteúdo mantida no Art. $16, \S 1^{\circ} \mathrm{e} \S 2^{\circ}$, contextos estes que foram objeto da ADI n. 3481. Por isso, esses incisos do 
Art. 16 também ficariam inviabilizados na Resolução 09/2018. Para explicitar, segue a íntegra do que trata o artigo objeto de contestação:

Art. 16 - Todos os testes psicológicos estão sujeitos ao disposto nesta Resolução, considerando que: $\$ 1$ - Os manuais de testes psicológicos devem informar que sua comercialização e seu uso é restrito a psicólogas e psicólogos, regularmente inscritos no CRP. $\$ 2^{\circ}$ - Na comercialização de testes psicológicos, as editoras manterão procedimento de controle, no qual conste o nome da psicóloga e do psicólogo que os adquiriu, o seu número de inscrição no CRP e o(s) número(s) de série dos testes adquiridos (CFP, 2018).

Cabe elucidar que a decisão do Supremo Tribunal Federal passa a vigorar imediatamente, salvo se o próprio STF tiver alguma disposição em contrário. Contudo, quando a decisão atenta contra a segurança jurídica ou ao interesse social, há como o STF modular os efeitos da declaração de inconstitucionalidade, podendo inclusive decidir que tal decisão passe a vigorar somente a partir do trânsito em julgado (quando o processo não tem mais ações no STF oriundas da decisão). Todavia, como nesse momento há um recurso de embargos de declaração proposto pelo CFP em trâmite, considera-se que a ação ainda está em andamento, podendo sobrevir mudanças na decisão.

\section{Da lógica jurídica de um recurso de embargos de declaração}

Assim que ocorreu a publicização, por meio do acompanhamento do julgamento, não oficial da decisão do STF em relação à ADI no 3481 , o Conselho Federal de Psicologia entrou, em 23 de março de 2021, com uma medida cautelar, buscando modulação pro futuro dos efeitos da decisão. Nessa ação inicial, antes da publicação da decisão oficial do STF por meio do acórdão indicava-se a necessidade de que houvesse uma modulação na decisão, de modo a considerar a variável temporal, isto é, o tempo para estabelecer os trâmites junto ao sistema de orientação e fiscalização do Sistema Conselhos de Psicologia, bem como para realizar as mudanças necessárias no próprio Sistema de Avaliação dos Testes Psicológicos (SATEPSI) para que a decisão começasse a vigorar.
Contudo, com o resultado oficial da ação com os respectivos votos proferidos publicados em acórdão no Diário da Justiça Eletrônico do dia 4 de abril de 2021, iniciou-se a contagem do prazo de dez dias úteis que uma autarquia federal, como é o Conselho Federal de Psicologia, tem para dar entrada nos embargos de declaração, pois os embargos devem ser apresentados após a publicação do acórdão, por constarem nele a integralidade dos votos dos ministros, dentre outras ações finais. Então, foi protocolado, no dia 20 de abril de 2021, o recurso de embargos de declaração, somando-se aos votos divergentes já sinalizados por quatro ministros na ocasião do julgamento da ADI. Cabe elucidar que, com o protocolo dos embargos de declaração, a ação da medida cautelar, protocolada no dia 23 de março de 2021, foi integrada nessa ação maior proposta pelos embargos.

Os embargos de declaração, ou embargos declaratórios, se referem a um tipo de recurso jurídico contra qualquer decisão judicial com o objetivo de elucidar alguma possível contradição ou uma omissão que possa ter ocorrido em alguma decisão proferida. Essa ação não tem a intenção de alterar o cerne da decisão, mas explicitar aspectos dessa decisão que não foram suficientemente discutidos e nem abordados de forma adensada, e, assim, obter uma modulação da decisão judicial (Tribunal de Justiça do Distrito Federal e dos Territórios, 2021).

Por essa via não se tem como propósito novamente discutir o mérito da ação de inconstitucionalidade. O objetivo é explicitar que a vigência imediata dos efeitos da decisão poderia acarretar impactos danosos à sociedade, à produção científica na área e ao funcionamento estrutural do Sistema Conselhos de Psicologia que impacta, por sua vez, a vida profissional de 389 mil psicólogos.

Portanto, uma das linhas de argumentação na ação dos embargos de declaração é justamente adensar a discussão de que a liberação da comercialização de testes psicológicos geraria, para toda a sociedade, prejuízos nas esferas pública e privada. Também se traça uma linha motriz que indica ao STF a necessidade de que haja uma desvinculação daquilo que é informação teórica e científica contidas nos manuais dos testes, e que poderiam ser divulgadas para não psicólogos, daquilo que constitui tecnologia profissional da prática psicológica e que, portanto, mereceria ser preservada. Ou seja, busca-se desvincular as pesquisas científicas que fundamentam teórica e empiricamente a cons- 
trução e o uso dos testes psicológicos, o que, em sua maioria, já se encontra disponível gratuitamente em periódicos científicos, daquilo que consiste no gabarito, nos itens dos testes, na explicitação das respostas socialmente mais aceitáveis ou reprováveis no teste e suas respectivas interpretações. Essas discussões são desenvolvidas nos textos dos embargos de declaração e problematizam os sérios problemas gerados pela abertura irrestrita aos testes psicológicos.

\section{Motivos para restrição de acesso aos testes psicológicos}

Muitos profissionais do direito não estão cientes de como a liberação irrestrita da compra dos testes psicológicos à população em geral pode afetar a segurança dos exames psicológicos que fazem uso deste importante instrumento. Hoje, os manuais dos testes contêm não apenas sua fundamentação teórica e os estudos empíricos que evidenciam suas propriedades científicas - cuja divulgação não interferirá no uso desses instrumentos, pois em grande parte já está disponível em artigos científicos -, como também seus itens e suas normas de correção e interpretação, nas quais há a indicação de quais respostas são mais socialmente desejadas, ou gabaritos que indicam quais são respostas certas e erradas a cada item. Estas últimas questões têm um imenso potencial de gerar prejuízos para a sociedade, para o indivíduo e para os profissionais da área.

Em síntese, a segurança do teste é fundamental para que as avaliações psicológicas atendam aos seus objetivos. Particularmente, a título de exemplo, quando os testes são usados em contextos compulsórios, ou seja, no âmbito de avaliações de caráter obrigatório que o indivíduo deve realizar por alguma imposição legal em cumprimento a alguma exigência normativa, é indispensável que ele mantenha sua natureza sigilosa (Faiad \& Alves, 2018). Embora o teste seja utilizado em todos os contextos profissionais do psicólogo, um exemplo importante são as avaliações compulsórias, pois nesse contexto ele oferece maior agilidade e suporte às tomadas de decisão dos psicólogos em seus cotidianos e, por isso, a excelência técnica e o cuidado ético devem nortear suas aplicações.

A liberação dos testes à população pode vir a facilitar os estudos das respostas de um teste pelos respondentes. A consequência disso seria propiciar um contexto de possível falseamento das respostas em diversos contentos no qual um perfil psicológico patológico ou muito desorganizado poderia ser tanto um risco para a própria pessoa como também para a comunidade em que ela está inserida.

O acesso irrestrito a esse tipo de informação é análogo a fornecer antecipadamente a prova do Exame Nacional do Ensino Médio (Enem) com seu gabarito para os alunos do ensino médio que concorrem a vagas em universidade brasileira ou dar acesso aos advogados do gabarito do Exame da Ordem dos Advogados Brasileiros $(\mathrm{OAB})$ antes de realizarem suas avaliações ou, ainda, disponibilizar a médicos recém-formados o gabarito da prova de ingresso nos programas de residência médica. O acesso prévio às possíveis respostas dos testes pode tornar fácil o avaliado burlar suas respostas, resultando, assim, em um grande prejuízo social. O mesmo ocorreria com testes de atenção, memória, inteligência e assim por diante. Desta forma, o acesso restrito dos testes psicológicos aos profissionais capacitados a utilizá-lo e comprometidos eticamente com o seu conselho profissional deve ser mantido de forma que os testes continuem como instrumentos objetivos, confiáveis e imparciais para diagnósticos psicológicos e para identificação de problemas de saúde mental ou de comprometimentos do sistema nervoso central, por exemplo.

A tentativa do CFP de manter o uso restrito dos testes psicológicos no Brasil está de acordo com as diretrizes internacionais da International Test Commission (2003) e com os padrões da American Psychological Association (2021), da Standards for Educational and Psychological Testing, da American Education Research Association, da National Council on Measurement in Education (Frey, 2018), da Canadian Psychological Association, da Australian Psychological Society e da National Academy of Neuropsychology - NAN (2003). De acordo com todas essas instituições, que atuam em diferentes nações ou contextos culturais, os usuários dos testes têm a responsabilidade de proteger a segurança desses instrumentos devido às consequências deletérias do seu acesso irrestrito. Além disso, essas instituições consideram que caso um teste psicológico tenha sua credibilidade questionada por meio da exposição ao domínio público, o desenvolvimento de um substituto seria um empreendimento dispendioso, tanto do ponto de vista financeiro quanto do temporal, pois construir testes psicológicos e analisar suas qualidades psicométricas é tarefa hercúlea.

Adicionalmente, permitir o acesso irrestrito aos testes possivelmente prejudicaria os direitos autorais e os interesses de propriedade intelectual dos autores 
e editores dos testes. Com o comprometimento dos testes psicológicos por meio de exposição pública, talvez os testes tenham que ser rapidamente substituídos. Esses são aspectos que serviriam como desincentivo para desenvolvedores e editores de teste em potencial, inibindo avanços científicos e clínicos e podendo levar os melhores pesquisadores da área a migrar para o exterior (NAN, 2003).

Diante de tudo o que foi exposto, a decisão do STF pode vir a acarretar problemas, pois desnatura os instrumentos que levaram anos de estudos científicos para serem alcançados, impactando significativamente na produção de conhecimento psicológico, no trabalho do psicólogo, e, sobretudo, na sociedade que, em última instância, é a beneficiária dos serviços prestados pela psicologia. Desse modo, entende-se que é necessário desenvolver estratégias para que o acesso à informação científica possa ser disponibilizado, assegurando os princípios constitucionais, sem, contudo, inviabilizar o uso dessa tecnologia profissional.

\section{Impactos da decisão de liberação dos testes para venda}

Os impactos sociais decorrem, como já mencionado, do uso inadequado dos testes psicológicos em duas principais direções: a) pelas consequências ao indivíduo; e b) pelas consequências sociais da avaliação. Cada uma delas será discutida a seguir.

O uso de um teste psicológico exige competências específicas que são desenvolvidas ao longo do curso de psicologia, conforme pode ser constatado nas Diretrizes Curriculares Nacionais dos Cursos de Psicologia (Conselho Nacional de Educação [CNE], 2011, 2019). O objetivo das diretrizes é nortear a implementação e a avaliação de cursos de ensino superior de psicologia. Para tanto, a formação do psicólogo deve incluir fundamentos epistemológicos e históricos; fenômenos e processos psicológicos; questões metodológicas que envolvem a pesquisa e a prática profissional, entre outros conteúdos não menos relevantes.

No que respeita à avaliação psicológica, constitui-se em campo prático de pesquisa e de ensino desde os primórdios da profissão no Brasil. Sua definição é retratada em documentos, obras clássicas, artigos de pesquisa, assim como na Resolução CFP No 009/2018, que a estabelece como: “. . . um processo estruturado de investigação de fenômenos psicológicos, composto de métodos, técnicas e instrumentos, com o objetivo de prover informações à tomada de decisão, no âmbito individual, grupal ou institucional, com base em demandas, condições e finalidades específicas" (CFP, 2018).

Assim, o teste psicológico compõe o processo de avaliação psicológica e, para que seu uso seja adequado, é imperioso que ocorra inserido em um processo no qual outras informações, além das obtidas pelo teste, sejam coletadas e analisadas conjuntamente de forma fundamentada na ciência psicológica. O que se pretende, ao final de uma avaliação psicológica, é elaborar uma resposta a uma determinada demanda psicológica.

Retomando as competências assinaladas anteriormente, a principal para o uso de testes psicológicos é o conhecimento teórico e prático sobre a área de avaliação psicológica. Tais competências podem ser adquiridas nos cursos de Psicologia e aprimoradas por meio de especializações lato sensu em avaliação psicológica que buscam melhorar a formação profissional (Primi, 2010). É imprescindível destacar que o conhecimento teórico e prático da avaliação psicológica depende de diversas outras competências (Muniz, 2017; Nunes et al., 2012; Perez, 2021). Esses textos expõem a complexidade e a necessidade de conhecimento de campos diversos da ciência psicológica, como o desenvolvimento humano, as psicopatologias e a psicometria, para realizar uma avaliação psicológica com qualidade técnica, ética e científica.

Dada a natureza complexa, formada por conhecimentos gerais da psicologia e específicos do campo da investigação e análise psicológica, ao longo de mais de uma década um movimento organizado por estudiosos, professores, pesquisadores, profissionais e associações científicas nacionais da avaliação psicológica destinaram esforços para que a área fosse reconhecida pelo CFP como uma das especialidades do profissional psicólogo. Em dezembro de 2018, na Assembleia de Políticas, Administração e Finanças (APAF) do Sistema Conselhos foi aprovada a solicitação desse movimento, culminando na Resolução CFP No 018/2019 que traz o papel, as funções e as competências que um profissional especialista de avaliação psicológica deve demonstrar.

Dentre as competências mencionadas nos textos e na resolução supracitada, está o uso adequado dos testes psicológicos. O teste psicológico é um instrumental da ciência psicológica utilizado em processos de avaliação psicológica para, em conjunto com outros instrumentos, técnicas e métodos, auxiliar no 
entendimento de uma demanda psicológica. Cabe ressaltar que o teste psicológico é uma fonte fundamental, constituindo-se em uma ferramenta que cientificamente comprovada por pesquisas empíricas para demonstrar sua qualidade e relevância em uma avaliação psicológica e que “. . . tem por objetivo identificar, descrever, qualificar e mensurar características psicológicas, por meio de procedimentos sistemáticos de observação e descrição do comportamento humano, nas suas diversas formas de expressão, acordados pela comunidade científica" (CFP, 2018).

Então, o teste é uma ferramenta de coleta de informações das características psicológicas de uma pessoa, grupo ou instituição que deve ser utilizado dentro de uma avaliação psicológica para que as informações advindas do teste sejam interpretadas de maneira coerente e justa a partir de demais dados obtidos por meio de outras técnicas, testes e métodos psicológicos. Assim, o que se observa a partir de um teste apenas terá utilidade e promoverá o benefício que se espera se for usado dentro desse processo específico de avaliação.

A liberação da venda dos testes psicológicos ao público em geral poderá trazer danos de grande monta ao indivíduo, que não terá competência suficiente para administrar os resultados de maneira adequada caso faça uso não permitido. já que ele é restrito ao psicólogo. Nesse ponto, é importante destacar que não haverá controle desse tipo de uso pelos compradores, uma vez que ao adquirir o teste, os indivíduos poderão a qualquer momento e em qualquer lugar aplicarem o teste em si próprio ou em alguém, como, por exemplo, no filho. Aqui reside a diferença entre o uso do teste por um psicólogo e por uma pessoa sem formação. A segunda não compreenderá que pesquisas de evidências de validade e a estimativa de precisão de um teste são conduzidas com o intuito de comprovar sua cientificidade. Os resultados supostamente discrepantes podem ser interpretados sob diferentes perspectivas teórica e metodológicas, como elementos de viés de resposta cujo detalhamento não se aplica ao presente artigo. Nesse mesmo sentido, o teste tem alcances limitados, dada a complexidade subjetiva do ser humano construída a partir de um contexto sócio-histórico, de modo que, para além da qualidade da ferramenta utilizada, é preciso ter o conhecimento da ciência psicológica para interpretar seus resultados adequadamente.

A segunda problematização refere-se aos impactos sociais da decisão sobre a venda irrestrita dos testes psicológicos. A ciência psicológica estuda há mais de um século as variáveis do funcionamento psicológico e as estratégias para captar sua amplitude por meio de testes psicológicos (Bueno \& Peixoto, 2018). É sabido que o uso dos testes precisa ser realizado por profissionais competentes que sabem como utilizá-los e que tenham o conhecimento necessário para interpretá-los. Dentre estas competências, estão as avaliações multimétodo, com o uso de diferentes instrumentos psicológicos com formatos diferentes para a coleta de informações (Primi, 2010). Uma de suas vantagens é possibilitar compreensões mais apropriadas do funcionamento psicológico de uma pessoa com vistas a diminuir os erros advindos de problemas, como as discrepâncias entre os dados, que devem ser analisadas perante a ciência psicológica.

Se indivíduo se aplicar o teste psicológico em si próprio, ele não fará uso competente, pois não saberá nem os limites desse instrumental nem como maximizar seu potencial em uma avaliação psicológica. O leitor pode imaginar o quão perigoso isso será para o indivíduo e quais são as consequências infrutíferas à prática profissional do psicólogo. Isso atenta de forma negativa em vários processos que envolvem avaliação psicológica, como a seleção dos melhores profissionais para determinados cargos, a determinação de condições do indivíduo para dirigir um veículo motorizado ou a avaliação de sua capacidade para manusear armas de fogo?

Para melhor entender a natureza e a complexidade de um teste e sua interpretação é necessário detalhá-lo melhor. O teste é constituído de itens ou estímulos relacionados a um determinado construto psicológico e, por meio das respostas a esses itens ou estímulos se avalia amostras do comportamento de uma pessoa de acordo com o conteúdo explícito do item ou do conteúdo específico a ser captado pelo estímulo proposto. Para elucidar esse ponto, toma-se como exemplo a avaliação da inteligência de acordo com o modelo Cattell-Horn-Carrol das Habilidades Cognitivas (CHC) (Schneider \& McGrew, 2018), segundo o qual há dezesseis capacidades amplas da inteligência, cada uma composta por capacidades específicas que, por sua vez, são avaliadas por meios de diferentes tarefas.

Um dos testes de inteligência mais utilizado no mundo, e considerado padrão-ouro para avaliar esse construto, são as Matrizes Progressivas de Raven (Paula et al., 2018), que avaliam o raciocínio indutivo, uma 
capacidade específica da capacidade ampla denominada raciocínio fluido. Outro instrumento bastante utilizado é a Escala Weschsler de Inteligência que, na quarta edição e disponível no Brasil, avalia cinco capacidades amplas (Santos et al., 2018). Como pode ser observado, ao se avaliar a inteligência é necessário ter o conhecimento teórico para compreender os limites de um teste e saber que ele não é capaz de avaliar o construto da inteligência como um todo, sendo necessário ponderar tais limitações e ter a competência de saber qual teste de inteligência utilizar a depender da demanda. Somado a isso, é mister que o profissional psicólogo também compreenda as possíveis limitações advindas da fundamentação utilizada em um teste. Isso não quer dizer que a teoria seja inadequada da teoria, mas sim que nenhuma teoria é capaz de abranger todas as possibilidades de um construto psicológico, podendo ocorrer divergências entre as abordagens. Aqui entra outra competência ao se utilizar um teste: escolher aquele que seja condizente com seus conhecimentos e com a abordagem de atuação para que se possa interpretá-lo de forma coerente com seu raciocínio clínico em uma avaliação.

Todas essas informações respaldam o enorme cuidado que se deve ter ao utilizar os escores do teste, obtidos e interpretados a partir de uma tabela normativa, que, por sua vez, indicará uma interpretação qualitativa pautada em uma teoria psicológica. Tais informações são primorosas quando acompanhadas de uma análise mais pormenorizada e contextualizada com outras referências que sustentam uma compreensão bem construída e pautada na ciência psicológica.

\section{Da ética profissional para os desdobramentos consequenciais}

Quando se considera o Código de Ética Profissional do Psicólogo, pode-se elencar algumas condutas que se relacionam diretamente com a prática da avaliação psicológica. Dentre elas, estão as alíneas c e i do artigo primeiro: "são deveres fundamentais do psicólogo: c) prestar serviço utilizando conhecimentos e técnicas reconhecidamente fundamentadas na ciência psicológica; i) zelar pela guarda, empréstimo, comercialização, aquisição e doação de material privativo do psicólogo (CFP, 2005).

Também no Art. $2^{\circ}$ constata-se as alíneas g, h e q:

g) ao psicólogo é vedado: emitir documento sem qualidade teórica, técnica e científica; h) interferir na validade e fidedignidade de instrumentos e técnicas psicológicas, adulterar seus resultados ou fazer declarações falsas; ... q) realizar diagnósticos, divulgar procedimentos ou resultados que exponham pessoas, grupos ou organizações; preservar o sigilo das informações (CFP, 2005).

Por fim, no artigo 18, novamente se fazem presentes condutas diretamente associadas à prática de avaliação psicológica: "não divulgar, ensinar, ceder, emprestar ou vender a leigos instrumentos e técnicas psicológicas que permitam ou facilitem o exercício ilegal da profissão" (CFP, 2005).

A conduta ética exigida de um psicólogo em sua prática profissional é algo que sofre orientação e fiscalização do Sistema Conselhos de Psicologia. Nesse sentido, diante do processo histórico de construção do Código de Ética Profissional do Psicólogo, criado para garantir a proteção da sociedade, o fazer profissional deste profissional é balizado pela conduta ética que assegura sua responsabilização.

Tal conduta ética depõe contra a facilitação para que pessoas não habilitadas tenham acesso irrestrito aos instrumentais do psicólogo. Se por um lado, o uso dos testes ainda continua restrito ao psicólogo, conforme preconiza a Lei no 4.119 , de 27 de agosto de 1962, no Art. 13:

Ao portador do diploma de Psicólogo é conferido o direito de ensinar Psicologia nos vários cursos de que trata esta lei, observadas as exigências legais específicas, e a exercer a profissão de Psicólogo.\$ $1^{\circ}$ - Constitui função privativa do Psicólogo e utilização de métodos e técnicas psicológicas com os seguintes objetivos: a) diagnóstico psicológico; b) orientação e seleção profissional; c) orientação psicopedagógica; d) solução de problemas de ajustamento (Lei no 4.119, 1962).

Por outro, a ação consequencial do acesso irrestrito pode ser o uso do instrumental por pessoas não especializadas, de modo que tais práticas irregulares não devem ser legitimadas. Chama-se a atenção que, embora seja possível a denúncia e a respectiva apuração devido ao exercício ilegal da profissão por não psicólogos, o ideal seria manter a segurança do procedimento e de seu conteúdo no uso restrito dos testes a partir da proteção e dos parâmetros éticos da profissão de psicólogo. 


\section{Considerações finais}

O presente artigo buscou apresentar o histórico do processo de liberação da comercialização dos testes psicológicos e uma crítica sobre suas possíveis consequências. Assim, a abertura da comercialização dos testes psicológicos, além de possibilitar que as pessoas leigas comprem os testes e os estudem para burlar um processo seletivo, como os realizados em concursos públicos e em outras avaliações compulsórias, abre uma possibilidade para que seja incorretamente usado, ainda que seu uso ainda esteja restrito ao psicólogo, podendo levar as pessoas a realizarem a autoadministração dos testes e se autodiagnosticarem equivocadamente. Essa segunda possibilidade poderá gerar um problema sério e irreversível de saúde pública, pois as pessoas, ao se depararem com algumas informações que possam as deixar preocupadas, poderão desencadear ou piorar problemas psicológicos, pois, além de estarem diante de informações que possam perturbar o equilíbrio psicológico, não estarão acompanhadas por um profissional psicólogo com capacidade para lidar com esse tipo de situação.

Cabe também ao Sistema Conselhos de Psicologia, por meio de sua Comissão Consultiva em Avaliação Psicológica, traçar ações que possam (re)pensar caminhos que assegurem uma prática profissional ética e comprometida socialmente na área de avaliação psicológica. Nesse ponto, deve se intensificar a articulação de ações formativas, orientativas e resolutivas que possam dar conta, caso a decisão do STF não sofra modulação, de garantir a segurança dos conteúdos oriundos dos processos de avaliações psicológicas por meio do uso de testes psicológicos balizados pela formação profissional do psicólogo. Face ao exposto, pode-se afirmar que as possibilidades dos caminhos ainda estão em construção e, diariamente, os desafios impostos estão sendo cada vez mais desvelados.

\section{Referências}

American Psychological Association. (2021). Maintaining test security in the age of technology. https://www.apa.org/ science/programs/testing/test-security-faq

Barroso, L. R. (2019). O controle de constitucionalidade no Direito Brasileiro. Saraiva.

Bueno, J. M. H., \& Peixoto, E. M. (2018). Avaliação Psicológica no Brasil e no Mundo [Número especial]. Psicologia: Ciência e Profissão, 38, 108-121. https://dx.doi.org/10.1590/1982-3703000208878

Conselho Federal de Psicologia. (2003). Resolução no 002, de 24 de março de 2003. Define e regulamenta o uso, a elaboração e a comercialização de testes psicológicos e revoga a Resolução CFP nº 025/2001.

Conselho Federal de Psicologia. (2003). Resolução CFP no 010/05. Aprova o Código de Ética Profissional do Psicólogo. https://site.cfp.org.br/wp-content/uploads/2005/07/resolucao2005_10.pdf

Conselho Federal de Psicologia. (2018). Resolução no 9, de 25 de abril de 2018. Estabelece diretrizes para a realização de Avaliação Psicológica no exercício profissional da psicóloga e do psicólogo, regulamenta o Sistema de Avaliação de Testes Psicológicos - SATEPSI e revoga as Resoluções no 002/2003, nº 006/2004 e n 005/2012 e Notas Técnicas no 01/2017 e 02/2017.

Conselho Nacional de Educação. (2011). Resolução no 5, de 15 de março de 2011. http://portal.mec.gov.br/index. php?option=com_docman\&view=download\&alias=7692-rces005-11-pdf\&Itemid=30192

Conselho Nacional de Educação. (2019). Parecer CNE/CES no 1071/2019. Câmara de Educação Superior. http://portal.mec.gov.br/index.php?option=com_docman\&view=download\&alias=139201-pces1071-19\&category_slug=dezembro-2019-pdf\&Itemid=30192

Faiad, C., \& Alves, I. C. B. (2018). Contribuições do Satepsi para Avaliações Psicológicas Compulsórias (Trânsito, Porte de Arma e Concursos Públicos) [Número especial]. Psicologia: Ciência e Profissão, 38, 50-59. https:// doi.org/10.1590/1982-3703000208851

Frey, B. B. (2018). (Ed.). The SAGE encyclopedia of educational research, measurement, and evaluation (Vols. 1-4). Sage Publications. https://doi.org/104135/9781506326139

International Test Commission (2003). Directrizes internacionais para a utilização de testes. https:/ /www.intestcom.org/ files/guideline_test_use_portuguese.pdf

Lei no 4.119, de 27 de agosto de 1962. Dispõe sobre os cursos de formação em Psicologia e regulamenta a profissão de psicólogo. http://www.planalto.gov.br/ccivil_03/leis/1950-1969/14119.htm 
Muniz, M. (2017). Competências e cuidados para a administração da avaliação psicológica e dos testes psicológicos. In M. R. C. Lins, \& J. Borsa (Orgs.), Avaliação Psicológica: Aspectos teóricos e práticos (pp.100-114). Vozes.

National Academy of Neuropsychology. (2013). Test Security: An update. https://nanonline.org/docs/PAIC/PDFs/ NANTestSecurityUpdate.pdf

Negretto, G. L. (2012). Replacing and amending constitutions: The logic of constitutional change in Latin America. Law \& Society Review, 46(4), 749-779. https://doi.org/10.1111/j.1540-5893.2012.00516.x

Nunes, M. F. O., Muniz, M., Reppold, C. T., Faiad, C., Bueno, J. M. H, \& Noronha, A. P. P. (2012). Diretrizes para o ensino de avaliação psicológica. Avaliação Psicológica, 11(2), 309-316.

Paula, J. J., Schlottfeldt, C. G. M. F., Malloy-Diniz, L. F., \& Mizuta, G. A. A. (2018). Matrizes Progressivas de Raven: Adaptação brasileira. Pearson Clinical Brasil.

Perez, A. J. S. (2021). Competências em avaliação psicológica. In K. L. Oliveira, M. Muniz, T. H. Lima, D. S. Zanini, \& A. A. A. Santos. Formação e estratégias de ensino em Avaliação Psicológica (pp. 35-58). Vozes.

Primi, R. (2010). Avaliação psicológica no Brasil: Fundamentos, situação atual e direções para o futuro [Número especial]. Psicologia: Teoria e Pesquisa, 26, 25-36. https:// doi.org/10.1590/S0102-37722010000500003

Santos, C. V. N. (2021). As audiências públicas e a ideia de que "o que não está nos autos não está no mundo. Brazilian Journal of Empirical Legal Studies, 8(19). https://doi.org/10.19092/reed.v8i.344

Santos, A. A. A., Muniz, M., Rueda, F. J. M., \& Martins, R. M. M. (2018). Validity evidence for the 4th edition of the Wechsler Intelligence Scale for Children. Psico, 49(1), 1-11. https://doi.org/10.15448/1980-8623.2018.1.27002

Schneider, W. J., \& McGrew, K. (2018). The evolution of the Cattel-Horn-Carroll (CHC) theory of intelligence. In D. P. Flanagan, \& Erin M. McDonough (Eds.), Contemporary intellectual assessment: Theories, tests and issues (pp. 73-173). Guilford Press.

Supremo Tribunal Federal (2021). STF veda limitação de acesso a testes psicológicos a profissionais habilitados. http://www.stf.jus.br/portal/cms/verNoticiaDetalhe.asp?idConteudo=462049

Tribunal de Justiça do Distrito Federal e dos Territórios (2021). Embargos de Declaração. https://www.tjdft.jus.br/ institucional/imprensa/campanhas-e-produtos/direito-facil/edicao-semanal/embargos-de-declaracao

\section{Ana Paula Porto Noronha}

Doutora em Psicologia pela Pontifícia Universidade Católica de Campinas. Membro da Comissão Consultiva em Avaliação Psicológica (CCAP). Bolsista Produtividade em Pesquisa 1A do CNPq. Docente do Programa de PósGraduação Stricto Sensu em Psicologia da Universidade São Francisco (USF), Bragança Paulista - SP. Brasil.

E-mail: ana.noronha8@gmail.com

(1) https://orcid.org/0000-0001-6821-0299

\section{Ana Cristina Resende}

Doutora em Psicologia pela Pontifícia Universidade Católica de Goiás (PUC-Goiás), com pós-doutorado em Psicologia Médica pela Universidade Federal de São Paulo. Membro da CCAP. Docente do Programa de PósGraduação Stricto Sensu em Psicologia da PUC-Goiás, Goiânia - GO. Brasil.

E-mail: anacristinaresende@hotmail.com

(1) https://orcid.org/0000-0001-5730-2577

\section{Katya Luciane de Oliveira}

Doutora em Psicologia, Desenvolvimento Humano e Educação pela Universidade Estadual de Campinas. Bolsista Produtividade em Pesquisa 2 do CNPq. Coordenadora da CCAP. Professora associada do curso de Psicologia e do Programa de Pós-Graduação em Psicologia da Universidade Estadual de Londrina (UEL), Londrina - PR. Brasil.

E-mail: katyauel@gmail.com

(1) https://orcid.org/0000-0002-2030-500X 


\section{Monalisa Muniz}

Doutora em Avaliação Psicológica pela USF. Membro da CCAP. Docente do Curso de Graduação e Pós-Graduação em Psicologia do Departamento de Psicologia da Universidade Federal de São Carlos (UFSCar), São Carlos - SP. Brasil.

E-mail: monamuniz@gmail.com

(1) https://orcid.org/0000-0003-1628-6296

\section{Caroline Tozzi Reppold}

Psicóloga com mestrado, doutorado e pós-doutorado em Psicologia pela Universidade Federal do Rio Grande do Sul. Membro da CCAP. Bolsista Produtividade em Pesquisa do CNPq 1-D. Professora associada da Universidade Federal de Ciências da Saúde de Porto Alegre (UFCSPA), Porto Alegre - RS. Brasil.

E-mail: reppold@ufcspa.edu.br

(1) https://orcid.org/0000-0002-0236-2553

Agradecemos ao Conselho Nacional de Desenvolvimento Científico e Tecnológico (CNPq) pelas bolsas de produtividade.

Endereço para envio de correspondência:

Rua Waldemar Cesar da Silveira, 105, Jardim Cura D’ars. CEP: 13045-510. Campinas - SP. Brasil.

Recebido 28/05/2021

Aceito 28/05/2021

Received 05/28/2021

Approved 05/28/2021

Recibido 28/05/2021

Aceptado 28/05/2021

Como citar: Noronha, A. P. P., Resende, A. C., Oliveira, K. L., Muniz, M., \& Reppold, C. T. (2021). Os Impactos da Ação Direta de Inconstitucionalidade no 3481 na Psicologia e na Sociedade. Psicologia: Ciência e Profissão, 41, 1-11. https://doi.org/10.1590/1982-3703003252730

How to cite: Noronha, A. P. P., Resende, A. C., Oliveira, K. L., Muniz, M. M., \& Reppold, C. T. (2021). The Impacts of Direct Action of Unconstitutionality 3481 on Psychology and Society. Psicologia: Ciência e Profissão, 41, 1-11. https://doi.org/10.1590/1982-3703003252730

Cómo citar: Noronha, A. P. P., Resende, A. C., Oliveira, K. L., Muniz, M., \& Reppold, C. T. (2021). Los Impactos de la Acción Directa de Inconstitucionalidad 3481 en la Psicología y la Sociedad. Psicologia: Ciência e Profissão, 41, 1-11. https://doi.org/10.1590/1982-3703003252730 